\title{
PENGEMBANGAN APLIKASI GAME MUSIK TRADISIONAL BALI MEGAMELAN BERBASIS MULTIPLATFORM
}

\section{Komang Aribawa ${ }^{1}$, I Gede Mahendra Darmawiguna ${ }^{2}$,} Gede Aditra Pradnyana ${ }^{3}$

\author{
${ }^{1,2,3}$ Fakultas Teknik \& Kejuruan Universitas Pendidikan Ganesha \\ Email : ${ }^{1}$ komangaribawaa@gmail.com, ${ }^{2}$ mahendra.darmawiguna@ undiksha.ac.id, ${ }^{3}$ gede.aditra@undiksha.ac.id
}

(Naskah masuk: dd mmm yyyy, diterima untuk diterbitkan: dd mmm yyy)

\begin{abstract}
Abstrak
Gong Kebyar adalah salah satu gamelan baru yang merupakan perkembangan dari dihilangkannya beberapa instrument dari Gamelan Gong Gede. Gamelan Gong Kebyar dugunakan untuk mengiringi tari-tarian dan juga untuk menyajikan gending-gending Pategak (musik instrumental). Penelitian ini bertujuan untuk (1) Mengimplementasikan aplikasi game musik tradisional Bali Megamelan berbasis multiplatform. (2) Untuk mengetahui respon pengguna terhadap pengembangan aplikasi game musik tradisional Bali Megamelan berbasis multiplatform. Aplikasi ini dikembangkan menggunakan metode ADDIE (analyze, design, development, implementation \& evaluation). Dengan dikembangkannya aplikasi ini, diharapkan masyarakat dapat mengenal dan belajar memainkan gamelan khususnya Gamelan Gong Kebyar. Seluruh Kebutuhan fungsional aplikasi ini telah berhasil diimplementasikan sesuai dengan rancangannya. Secara umum aplikasi mendapatkan respon sangat baik dilihat dari beberapa hasil pengujian angket. : a) uji ahli isi dengan persentase $92 \%$, b) uji ahli media dengan persentase $93 \%$ dan c) uji respon dengan hasil persentase $94 \%$.
\end{abstract}

Kata kunci: Game, Instrumen, Gamelan Gong Kebyar, Multiplatform.

\begin{abstract}
Gamelan Gong Kebyar is a new Gamelan which is the development of Gong Gede in which several of its instruments have been removed. Gamelan Gong Kebyar was used to accompany dances and present Gending Pategak (instrumental music). This research aims to (1) Implementing the application of Traditional balinesse Music Game namely Megamelan which is based on multiplatform device. (2) Find out users' responses toward the development of Traditional balinese Music Game namely Megamelan which is based on multiplatform device. This application was developed by using ADDIE (analyze, design, development, implementation \& evaluation). In relation to the development of this application, it is expected that people are able to recognize and learn playing Gamelan especially Gamelan Gong Kebyar. All functional requirements of this application has been successfully implemented in accordance to the plan. Generally, this application can get excellent responses that can be seen from several test results of questionnaire. a) Expert test contents with $92 \%$ percentage, b) Media expert test with 93\% percentage and c) Response test with $94 \%$ percentage.
\end{abstract}

Keywords: Game, Instrument, Gamelan Gong Kebyar, Multiplatform.

\section{PENDAHULUAN}

Indonesia sangat banyak memiliki kebudayaan yang dapat dibanggakan, salah satunya adalah alat musik tradisional. Menurut Sedyawati musik tradisional adalah musik yang digunakan sebagai perwujudan dan nilai budaya, sesuai dengan tradisi (Isbat, 2014). Menurut Tumbijo Musik tradisional adalah seni budaya yang sejak lama turun temurun yang telah hidup dan berkembang pada daerah tertentu (Wibowo, 2014). Maka dapat dijelaskan bahwa musik tradisional adalah musik masyarakat yang diwariskan secara turun - temurun dan berkelanjutan pada masyarakat dalam suatu daerah. Maka pengertian musik tradisional adalah cetusan ekspresi perasaan melalui suara atau melalui nada dari alat musik sehingga mengandung lagu atau irama yang diwariskan secara turun temurun dari satu generasi ke generasi berikutnya.

Setiap daerah di Indonesia memiliki musik tradisional dan tradisinya masing-masing. Gamelan merupakan salah satu alat musik yang paling populer dan dikagumi oleh warga Internasional. Seiring berjalannya waktu, gamelan khususnya di Bali ikut mengalami perkembangan. Gong kebyar adalah salah satu tanda munculnya pengaruh zaman terhadap kesenian di Bali. Gong Kebyar merupakan perkembangan dari Gong Gede yang beberapa instrumennya dihilangkan. Gong Kebyar merupakan 
suatu bentuk komposisi yang dihasilkan dengan memainkan seluruh alat gamelan secara serentak dalam aksentuasi yang poliritmik, dinamis, dan harmonis dengan teknik permainannya memakai sistem kebyar. Gong Kebyar berlaras pelog lima nada dan kebayakan instrumennya memiliki sepuluh sampai dua belas nada, karena konstruksi instrumennya yang lebih ringan jika dibandingkan dengan Gong Gede. Tabuh-tabuh Gong Kebyar lebih lincah dengan komposisi yang lebih bebas, hanya pada bagian-bagian tertentu saja hukum-hukum tabuh klasik masih dipergunakan, seperti tabuh Pisan, Tabuh Dua, Tabuh Telu dan sebagainya (Suharta, 2011).

Seiring perkembangan zaman, alat musik modern lebih banyak dimainkan daripada alat music tradisional. Kurangnya sosialisasi dan pengenalan akan budaya Indonesia di masyarakat merupakan salah satu faktor penting mengapa minat masyarakat menjadi kurang terhadap alat musik tradisional. Melihat hal tersebut tersebut, hendaknya masyarakat Indonesia berinisiatif untuk mulai melestarikan kebudayaan sendiri.

Game merupakan permainan yang menggunakan media elektronik, game adalah sebuah hiburan berbentuk multimedia yang dibuat semenarik mungkin agar pemain bisa mendapatkan sesuatu sehingga adanya kepuasan batin (Yudharto, 2010). Mengingat remaja sekarang lebih banyak menghabiskan waktunya dengan bermain game dibandingkan belajar, yang membuat wawasan mereka tentang kebudayaan negeri mereka sendiri menjadi sempit (Priawan, 2013). Pada dasarya game dibuat sebagai sarana hiburan saja, akan lebih baik jika game diciptakan untuk sarana belajar supaya anak-anak bisa lebih kreatif dalam berpikir.

Atas dasar inilah peneliti terdorong untuk menyelaraskan kemajuan teknologi dengan budaya. Seiring dengan berkembangnya teknologi, mobile device mulai banyak digunakan oleh seluruh lapisan masyarakat mulai dari kalangan menengah ke bawah hingga kalangan menengah ke atas, dengan demikian mobile device sangatlah tepat untuk digunakan sebagai media yang dapat dimanfaatkan atau dikembangkan sebagai alat bantu penyelarasan antara teknologi dengan budaya.

Beberapa penelitian mengenai pengembangan aplikasi musik tradisional telah diteliti ataupun dikembangkan oleh beberapa pihak. Penelitian dengan judul Pengembangan Aplikasi Instrumen
Gamelan Semar Pegulingan Berbasis Android (Diamika, 2015). Membahas mengenai permasalahan yang terdapat pada penelitian tersebut yaitu karena keberadaan Gamelan Semar Pegulingan sekarang tergolong langka. Adapun penelitian dengan judul Game Jegog Berbasis Android (Antara, 2014). Membahas mengenai permasalahan yang terdapat pada penelitian tersebut adalah guna untuk membantu pemerintah dalam memperkenalkan kembali kepada masyarakat terutama kaum remaja yang berusia dari 16 - 20 tahun tentang beberapa alat music tradisional Gamelan Gong Kebyar.

Berdasarkan pemaparan tersebut, adapun tujuan yang diharapkan dapat dicapai dari pengembangan aplikasi game musik tradisional Bali Megamelan ini adalah sebagai berikut : a) Untuk mengimplementasikan aplikasi game musik tradisional Bali Megamelan berbasis multiplatform. b) Untuk mengetahui respon pengguna terhadap pengembangan aplikasi game musik tradisional Bali Megamelan berbasis multiplatform.

\subsection{Gong Kebyar}

Gong Kebyar merupakan barungan baru. (Kebyar yang bermakna tiba-tiba, cepat dan keras) gamelan ini menghasilkan musik-musik dinamis dan keras. Secara fisik Gong Kebyar adalah pengembangan dari Gong Gede dengan pengurangan peranan, atau pengurangan beberapa buah instrumennya. Misalnya saja peranan trompong dalam Gong Gebyar dikurangi, bahkan pada tabuhtabuh tertentu tidak dipakai sama sekali, gangsa jongkoknya yang berbilah 5 dirubah menjadi gangsa gantung berbilah 9 atau 10. Cengceng kopyak yang terdiri dari 4 sampai 6 pasang dirubah menjadi 1 atau 2 set cengceng kecil. Kendang yang semula dimainkan dengan memakai panggul diganti dengan pukulan tangan Gamelan ini dipakai untuk mengiringi tari-tarian atau memainkan tabuh-tabuhan instrumental (Galang, 2014).

\section{METODOLOGI}

Metode yang digunakan dalam penelitian ini adalah metode ADDIE. Sesuai dengan namanya, model ADDIE terdiri dari lima tahapan yaitu Analysis (Analisis), Design (perancangan), Development (pengembangan), Implementation (implementasi), dan Evaluation (evaluasi) (Muruganantham, 2015). 


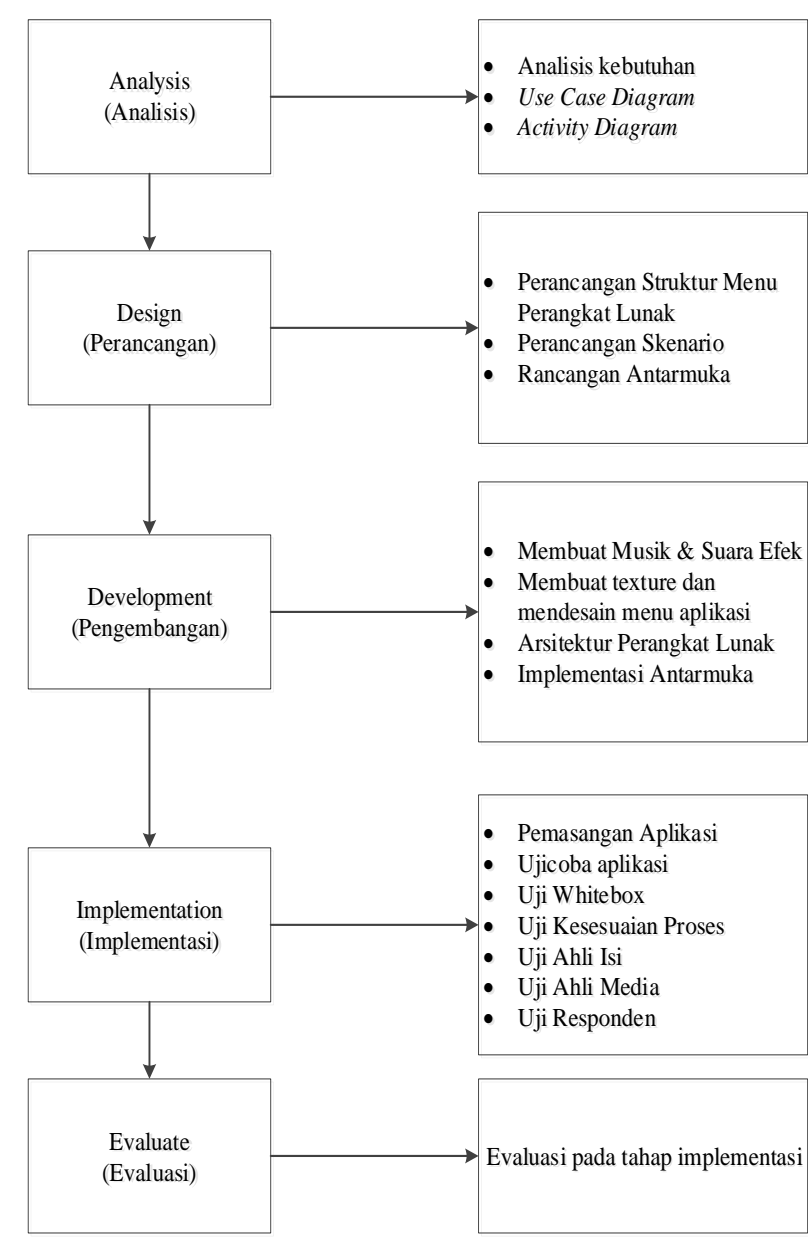

Gambar 1 Model Penelitian ADDIE pada Pengembangan Aplikasi Game Musik Tradisional Bali Megamelan Berbasis Multiplatform

\section{HASIL DAN PEMBAHASAN}

\subsection{Hasil Tahap Analysis}

Hasil penelitian pengembangan game Musik Tradisional Bali Megamelan dari model ADDIE dengan lima tahap, yaitu analysis, design, development, implementation, evaluation sebagai berikut.

\subsubsection{Analisis Masalah dan Usulan Solusi}

Pada tahap ini, peneliti mengidentifikasi masalah-masalah yang ditemukan sehingga dapat dijadikan acuan untuk mengembangkan aplikasi Game Musik Tradisional Bali "Megamelan". Pada tahap ini dilakukan analisis masalah dan solusi dengan menggunakan metode kuesioner dan metode observasi. Kuesioner yang digunakan yaitu kusesioner tertutup dengan menggunakan check list, dimana responden tinggal membubuhkan tanda check atau centang $(\sqrt{ })$ pada kolom yang sesuai. Berikut adalah kuesioner yang digunakan dalam pengembangan aplikasi game Megamelan music tradisional Bali

Tabel 1. Kuesioner Wawasan Mengenai Musik Tradisional Bali Gamelan

\begin{tabular}{|c|c|c|c|}
\hline No & Pernyataan & Ya & Tidak \\
\hline 1. & $\begin{array}{l}\text { Apakah anda generasi muda yang } \\
\text { tertarik dengan kesenian daerah } \\
\text { khususnya musik tradisional Bali } \\
\text { gamelan? }\end{array}$ & & \\
\hline 2. & $\begin{array}{l}\text { Saya mengetahui } r \text { musik } \\
\text { tradisional Bali Gamelan Gong } \\
\text { Kebyar. }\end{array}$ & & \\
\hline 3. & $\begin{array}{l}\text { Saya tertarik belajar bermain } \\
\text { musik tradisional Bali Gamelan } \\
\text { Gong Kebyar }\end{array}$ & & \\
\hline 4. & $\begin{array}{l}\text { Saya bisa bermain musik } \\
\text { tradisional Bali Gamelan Gong } \\
\text { Kebyar }\end{array}$ & & \\
\hline 5. & $\begin{array}{lrr}\text { Saya ingin } & \text { belajar mengetahui } \\
\text { nada-nada } & \text { dalam } r & \text { musik } \\
\text { tradisional Bali Gamelan Gong } \\
\text { Kebyar }\end{array}$ & & \\
\hline 6. & $\begin{array}{l}\text { Saya tertarik bermain game } \\
\text { Aplikasi Instrumen Gamelan } \\
\text { Semar Pegulingan. }\end{array}$ & & \\
\hline 7 & 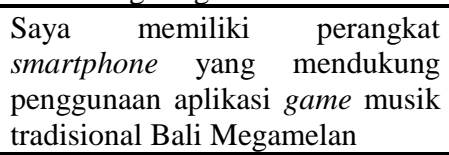 & & \\
\hline
\end{tabular}

\subsubsection{Analisis Kebutuhan}

Tahap analisis merupakan tahap pertama yang harus dilakukan seperti pengumpulan informasi dan kebutuhan secara lengkap kemudian dianalisis dan didefinisikan kebutuhan yang harus dipenuhi oleh aplikasi yang akan dibangun. Hal ini sangat penting mengingat aplikasi harus dapat berinteraksi dengan elemen-elemen lain seperti hardware dan software.

\subsubsection{Tujuan Pengembangan Aplikasi}

Adapun tujuan pengembangan perangkat lunak adalah sebagai berikut.

a. Menampilkan Main Menu yang terdiri dari Play Game, Learn To Play, High Score dan About.

b. Menampilkan antarmuka Level

c. Menampilkan antarmuka Setlist atau daftar lagu yang akan dipilih pemain.

d. Menampilkan antarmuka Game Mode yang menampilkan tangga nada yang harus diukuti oleh pemain.

e. Menampilkan skor saat permainan selesai.

f. Menampilkan antarmuka Learn to Play.

g. Menampilkan Antarmuka Instrumen

h. Menampilkan tentang pengembang aplikasi.

i. Keluar dari Aplikasi 


\subsubsection{Model Fungsional}

a. Use Case

Use case diagram menggambarkan fungsionalitas yang diharapkan dari sebuah sistem. Seorang/sebuah aktor adalah sebuah entitas manusia atau mesin yang berinteraksi dengan sistem untuk melakukan pekerjaan-pekerjaan tertentu.

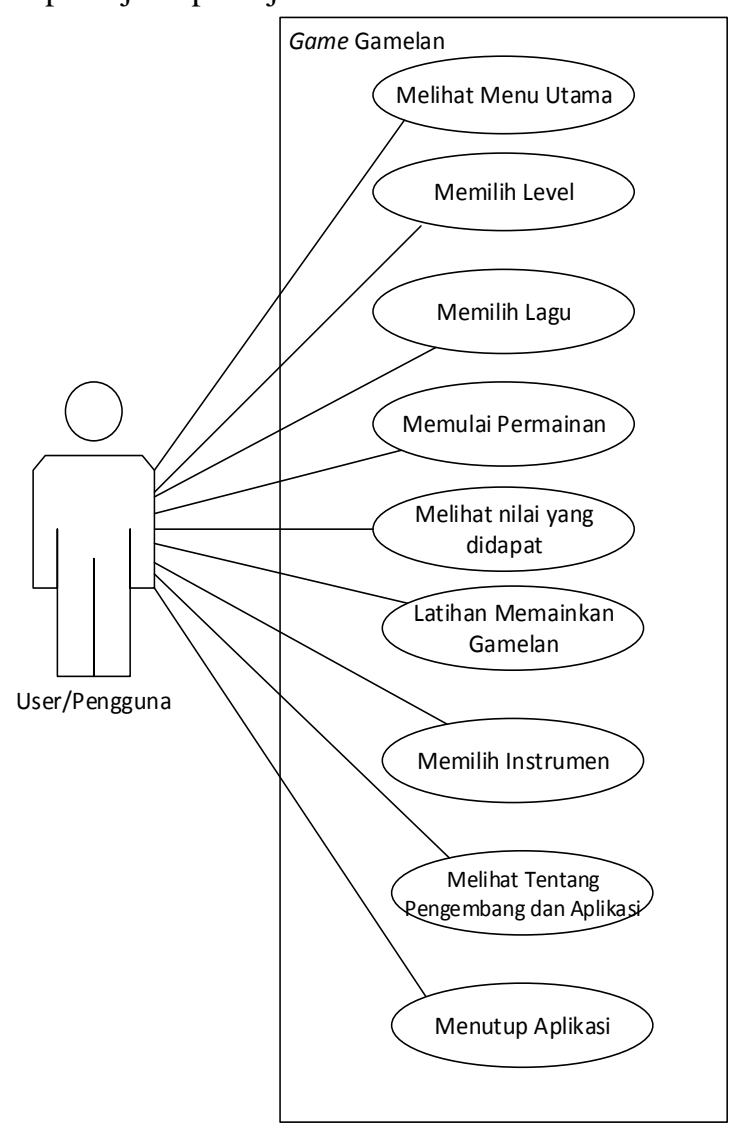

Gambar 2 Use Case Diagram

\subsection{Hasil Tahap Design}

\subsubsection{Arsitektur Sistem}

Perancangan struktur menu menampilkan berbagai menu yang tersedia pada aplikasi. Menumenu yang ada pada aplikasi digambarkan dalam bentuk hirarki. Tiap-tiap menu terhubung melalui garis yang menyatakan adanya hubungan dari satu menu ke menu yang lainnya. Perancangan struktur menu pada aplikasi ini dapat dilihat pada Gambar 4.2

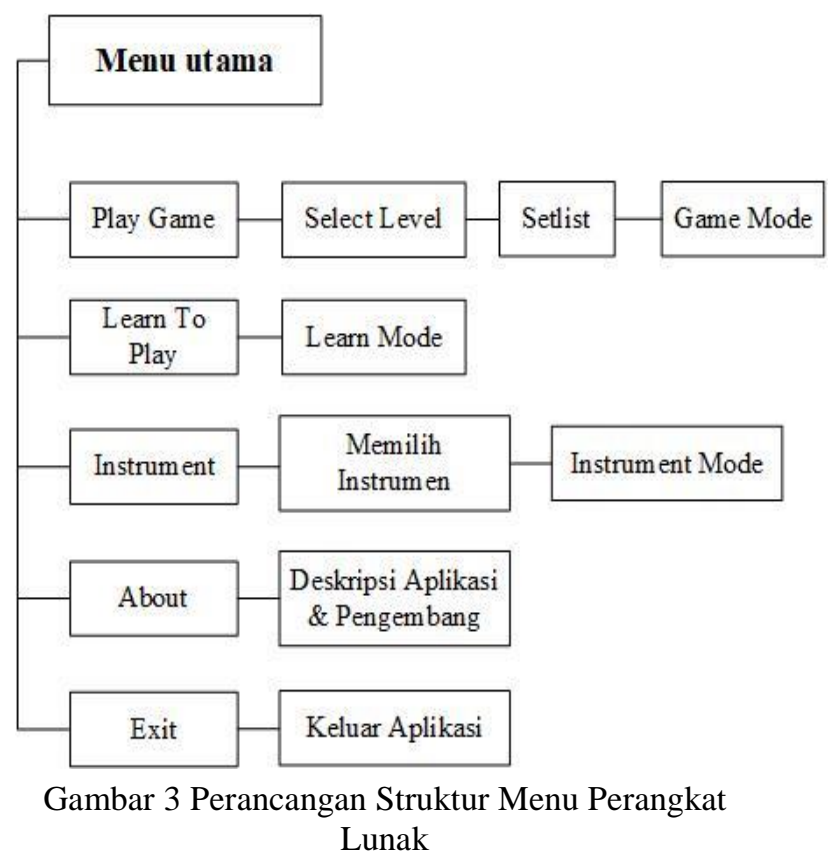

\subsubsection{Perancangan Skenario}

Skenario game merupakan bagian dari alur aplikasi dari game yang mendefinisikan setiap interaksi dari pemain. Sekenario ini digunakan agar game serasa lebih mudah untuk diarahkan sehingga tidak melebar dan sebagai alur penyimpanan materi game kepada pengguna agar dapat dipahami.

\subsubsection{Rancangan Antarmuka}

Pada tahap ini dilakukan perancangan antarmuka perangkat, yaitu membuat rancangan tampilan dari aplikasi game musik tradisional Bali Megamelan yang berfungsi untuk menghubungkan pengguna dengan perangkat lunak aplikasi agar dapat berinteraksi. Aplikasi ini memiliki rancangan antarmuka yang sederhana, mudah digunakan, dan dipahami oleh pengguna.

a. Rancangan Antarmuka Splash Screen

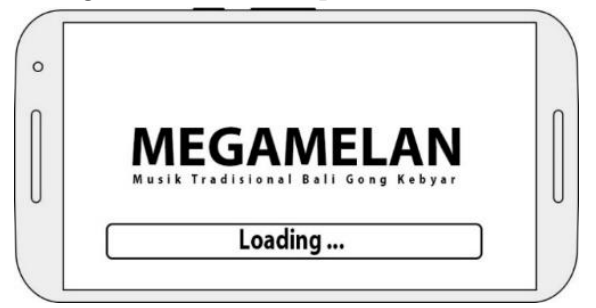

Gambar Error! No text of specified style in document. Rancangan Antarmuka Splash Screen

Gambar 4 merupakan rancangan antarmuka tampilan splash screen atau tampilan awal sebelum masuk ke main menu atau menu utama. 
b. Rancangan Antarmuka Main Menu

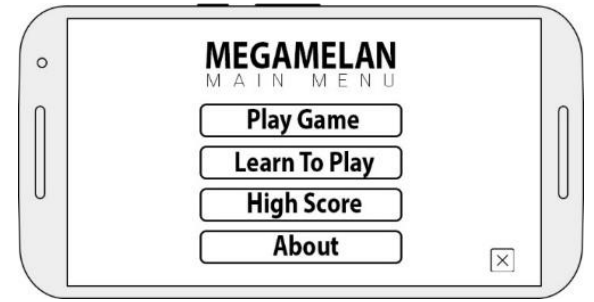

Gambar 5 Rancangan Antarmuka Main Menu

Gambar 5 merupakan rancangan antarmuka tampilan main menu atau menu utama dalam game. Aplikasi yang dikembangkan memiliki 4 menu utama, yaitu Play Game untuk memulai. Learn To Play yaitu latihan memainkan gamelan. High Score yaitu untuk menampilkan nilai tertinggi yang didapatkan pemain. About untuk menampilkan tentang identitas pengembang dan aplikasi

c. Rancangan Antarmuka Select Level

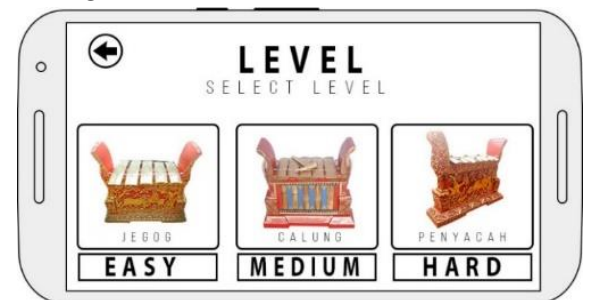

Gambar 6 Rancangan Antarmuka Select Level

Gambar 6 merupakan rancangan antarmuka tampilan select level atau pilihan tingkatan kesukaran dalam permainan. Dalam pengembangan aplikasi game musik tradisional Bali Megamelan ini terdapat 3 level, yaitu level Easy adalah level yang paling mudah yang menggunakan instrumen Jegog, level Medium yaitu level menengah yang menggunakan instrumen Calung, dimana ketukan dalam Calung memiliki 2 kali lebih cepat dari pada Jegog, dan yang terakhir adalah level Hard yaitu level yang paling susah yang menggunakan instrumen Penyacah yang memiliki ketukan yang paling banyak dari Jegog dan Calung.

\section{d. Rancangan Antarmuka Setlist}

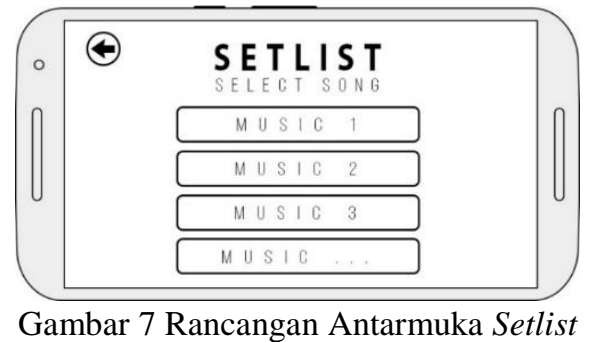

Gambar 7 merupakan rancangan antarmuka tampilan setlist atau pilihan lagu yang akan dimainkan. Pada scene ini pemain akan memilih lagu yang mau dimainkan. Pada setlist terdapat total 9 lagu yang dapat dimainkan oleh pemain.

\section{e. Rancangan Antarmuka Game Mode}

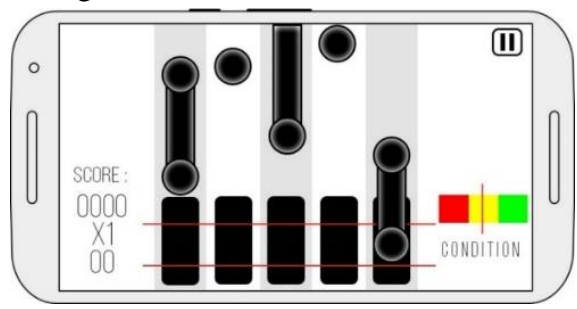

Gambar 8 Rancangan Antarmuka Game Mode

Gambar 8 merupakan rancangan antarmuka tampilan game mode. Pada game mode pemain dituntut harus menekan tangga nada ketika menyentuh area yang ditandai pada daun gamelan. Ketika garis condition berada pada warna hijau dan pemain tidak melakukan kesalahan maka score pemain akan dikalikan maksimal sampai $\times 4$. Sedangkan jika pemain terus melakukan kesalahan maka garis akan menuju warna merah maka permainan akan selesai.

f. Rancangan Antarmuka Learn To Play

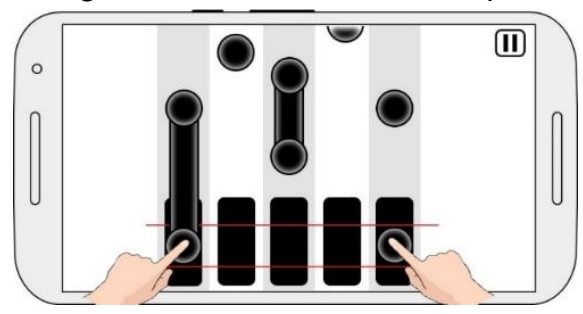

Gambar 9 Rancangan Antarmuka Learn To Play

Gambar 9 merupakan rancangan antarmuka tampilan learn to play atau belajar memainkan gamelan. Pada scene Learn To Play yaitu untuk belajar cara memainkan gamelan maka tidak terdapat score dan condition dalam mode ini.

g. Rancangan Antarmuka Select Instruments

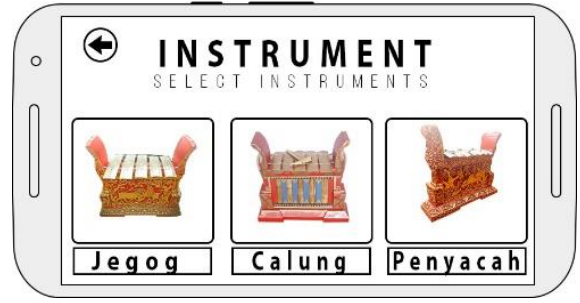




\section{Gambar 10 Rancangan Antarmuka Select Instruments}

Gambar 10 Rancangan antarmuka Select Instruments. Pada scene instruments yaitu untuk pemain dapat memilih Gamelan yang ingin dimainkan.

h. Rancangan Antarmuka Win Condition

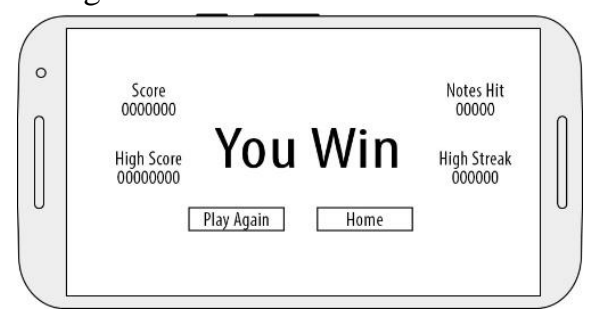

Gambar 11 Rancangan Antarmuka Win Condition

Gambar 11 merupakan scene Win Condition yaitu ketika pemain dapat menyelesaikan permainan.

i. Rancangan Antarmuka Lose Condition

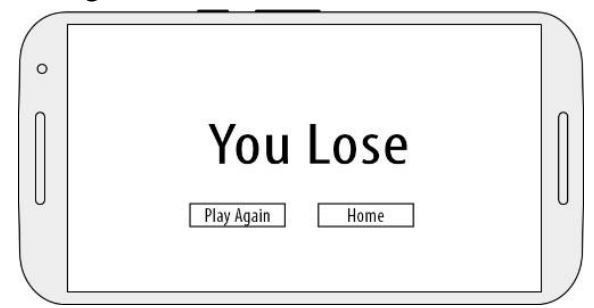

Gambar 12 Rancangan Antarmuka Lose Condition

Gambar 12 merupakan scene Lose Condition yaitu ketika pemain tidak dapat menyelesaikan permainan.

j. Rancangan Antarmuka Tentang Pengembang dan Aplikasi

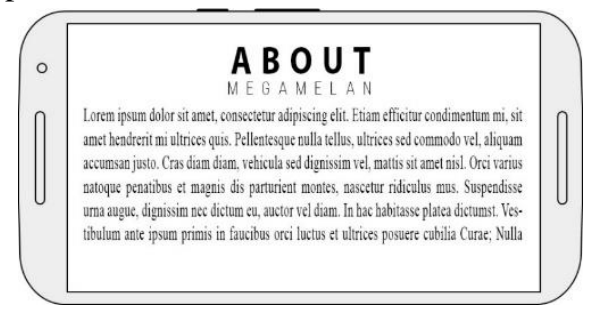

Gambar 13 Rancangan Antarmuka Tentang Pengembang dan Aplikasi

Gambar 13 merupakan scene About yaitu untuk menampilkan informasi tentang pengembang dan aplikasi. k. Rancangan Antarmuka Leave Game

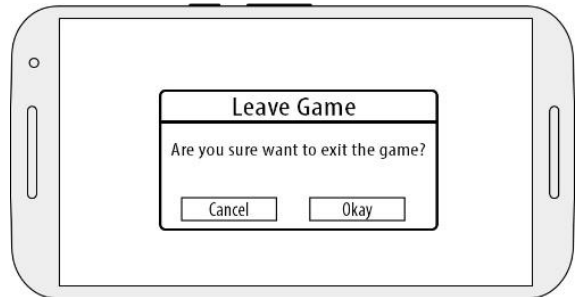

Gambar 15 Rancangan Antarmuka Leave Game

Gambar 15 merupakan rancangan antarmuka leave game yaitu untuk mengeluarkan aplikasi jika pemain menekan tombol okay. jika pemain menekan tombol cancel maka sistem kembali menampilkan menu utama.

\subsection{Hasil Tahap Development}

Hasil perancangan game Musik Tradisional Bali Megamelan memerlukan berbagai assets maupun aplikasi. Berikut adalah aplikasi yang digunakan dalam Pengembangan Aplikasi Game Musik Tradisional Bali Megamelan :

a. Game Multiplatform, aplikasi yang digunakan untuk mengembangkan adalah Unity 3D sebagai sebagai game engine untuk pengembangan aplikasi game yang berbasis multiplatform.

b. Grafis, aplikasi yang digunakan untuk mengembangkan adalah Adobe Photoshop untuk membuat texture dan mendesain menu aplikasi.

c. Musik dan Suara Efek, aplikasi yang digunakan untuk mengembangkan adalah Audacity, untuk memotong beberapa musik.

\subsubsection{Implementasi}

Adapun implementasi tampilan antarmuka Game Megamelan. Berikut adalah implementasi dari perancangan antarmuka pengguna :

a. Implementasi Antarmuka Splash Screen

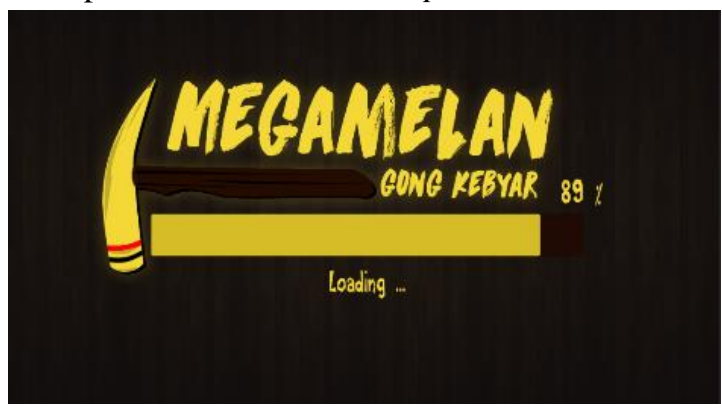

Gambar 16 Implementasi Antarmuka Splash Screen 
b. Implementasi Antarmuka Main Menu

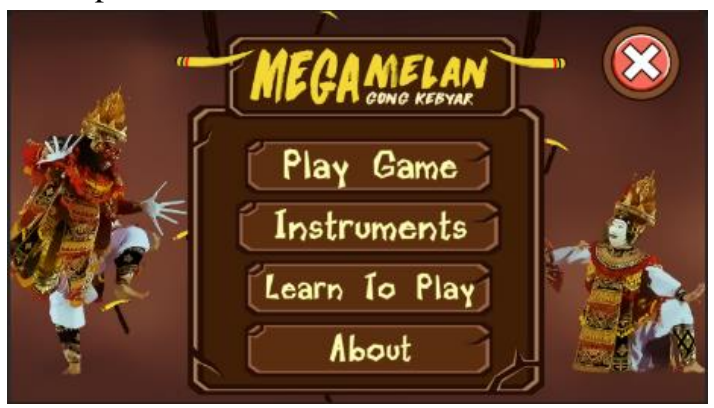

Gambar 17 Implementasi Antarmuka Main Menu

c. Implementasi Antarmuka Select Level

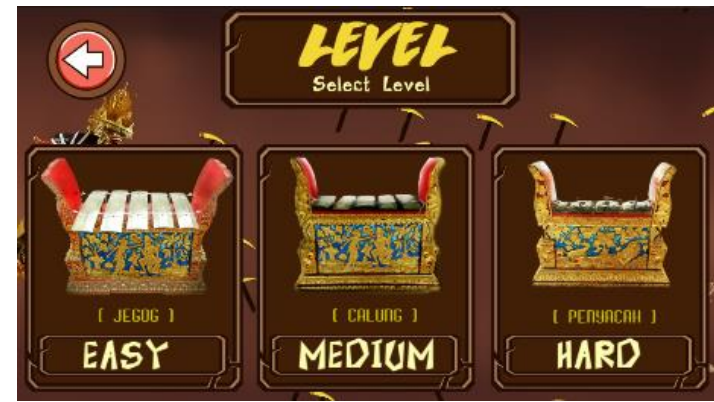

Gambar 18 Impelematasi Antarmuka Select Level

d. Implementasi Antarmuka Setlist

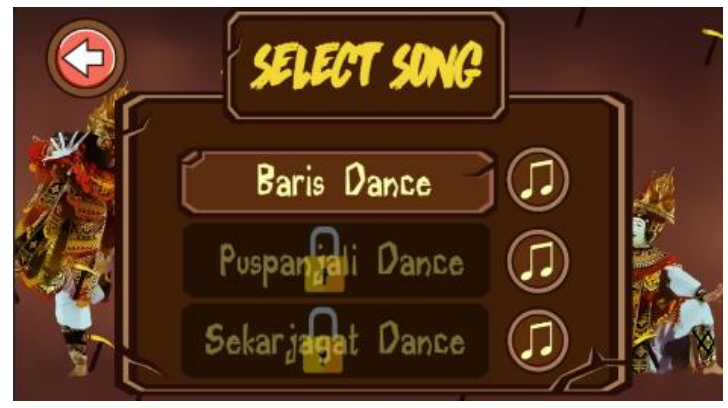

Gambar 4 Implementasi Antarmuka Setlist

Dalam implementasi antarmuka Setlist terdapat 3 bagian yang sesuai dengan level yang dipilih.

e. Implementasi Antarmuka Game Mode

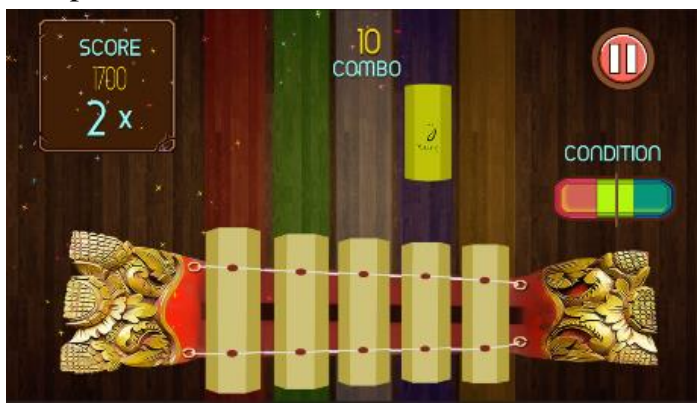

Gambar 19 Implementasi Antarmuka Game Mode f. Implementasi Antarmuka Learn To Play

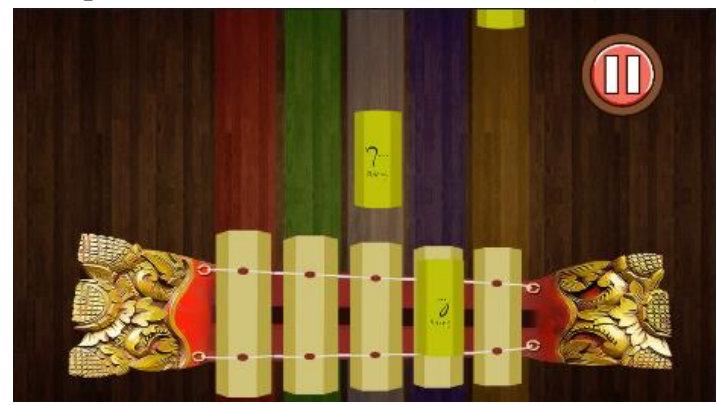

Gambar 20 Implementasi Antarmuka Learn To Play

g. Implementasi Antarmuka Win Condition

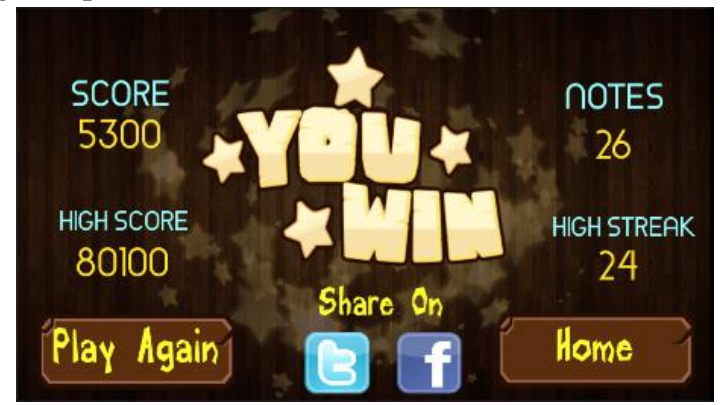

Gambar 21 Implementasi Antarmuka Win Condition

h. Implementasi Antarmuka Lose Condition

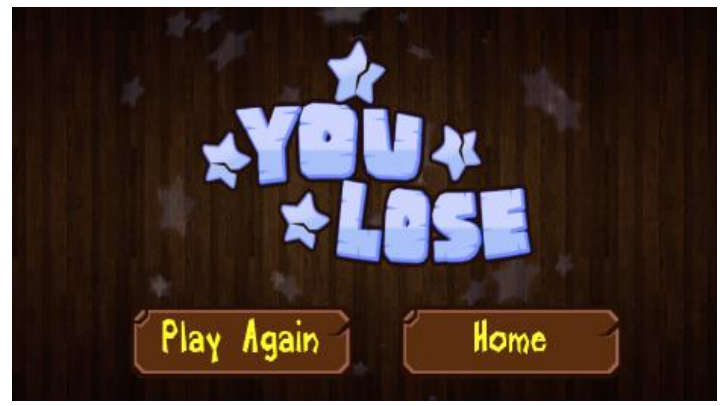

Gambar 22 Implementasi Antarmuka Lose Condition

i. Implementasi Antarmuka Tentang Pengembang dan Aplikasi

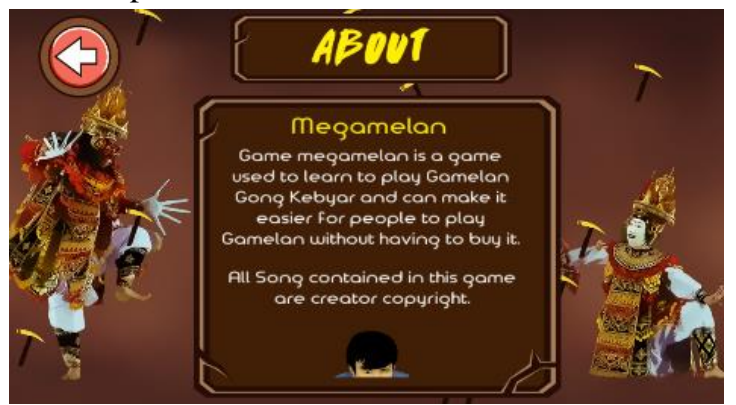

Gambar 23 Implementasi Antarmuka Tentang Pengembang dan Aplikasi 
j. Implementasi Antarmuka Leave Game

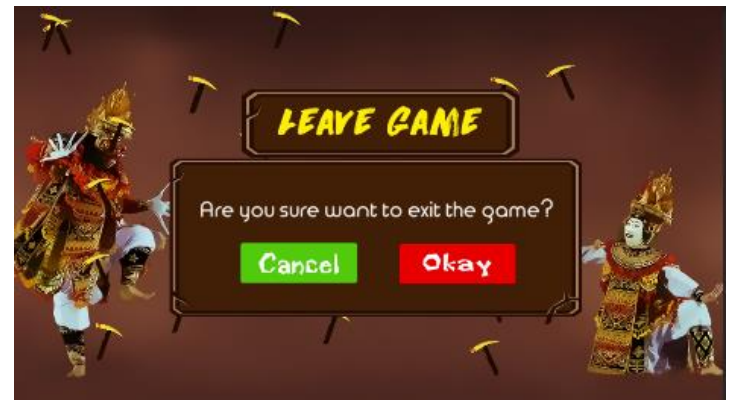

Gambar 24 Implementasi Antarmuka Leave Game

\subsection{Hasil Tahap Implementation}

Sebelum dapat digunakan, pengguna harus memasang aplikasi game musik tradisional Bali Megamelan. Agar aplikasi dapat dipasang di smartphone pengguna, smartphone tersebut harus memenuhi syarat minimal. Spesifikasi perangkat minimal yang diperlukan untuk menjalankan aplikasi adalah sebagai berikut.

a. Sistem Operasi Android

- Processor ARM-v7a

- GPU kelas mid-end

- $\quad$ RAM $512 \mathrm{MB}$

- $\quad$ OS Android versi 4.1 (jelly bean)

- Resolusi layar 320 x 480

b. Sistem Operasi iOS

$$
\begin{array}{ll}
\text { - } & 1.0 \mathrm{GHz} \text { Cortex-A8 } \\
\text { - } & 3,5 \text { inchi } \\
\text { - } & \text { RAM } 512 \mathrm{MB} \\
\text { - } & \text { Sistem Operasi iOS } 4
\end{array}
$$

Jika smartphone pengguna sudah diatas syarat minimum maka dapat dilanjutkan ke proses instalasi aplikasi. Untuk smartphone yang berbasis android dapat memasang aplikasi dengan membuka file APK yang telah dibuat menggunakan Unity. Berikut adalah proses instalasi dari aplikasi dengan smartphone yang berbasis Android.

\subsubsection{Proses Pemasang Aplikasi}

a. Membuka file Apk aplikasi

Pada tahap pertama pemasangan aplikasi ke smartphone Android adalah dengan cara membuka Apk aplikasi pada smartphone.

$$
<\text { APKs }
$$

\section{B Megamelan.apk}

54.12 MB | 9/18/2017 11:03

Gambar 25 Membuka File Apk Aplikasi b. Mengijinkan Aplikasi Yang Dipasang Dari Sumber Yang Tidak Diketahui

Pada tahap kedua yaitu mengijinkan aplikasi dipasang dari sumber yang tidak diketahui. Karena aplikasi dipasang tidak lewat Google Play Store, maka perlu mengijinkan aplikasi untuk dipasang.

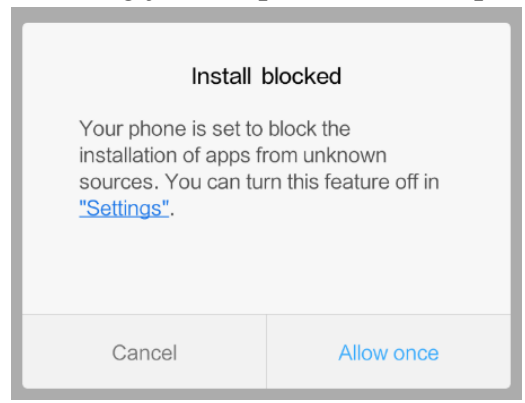

Gambar 26 Mengijinkan Aplikasi Yang Dipasang Dari Sumber Yang Tidak Diketahui

c. Menekan Tombol Instal

Tahap ketiga yaitu menekan tombol instal untuk memulai proses pemasangan aplikasi pada smartphone

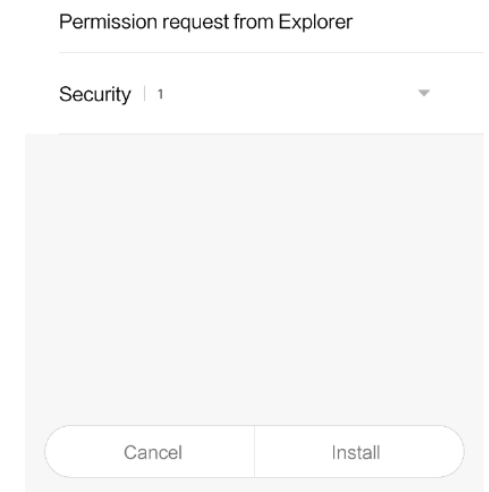

Gambar 27 Menekan Tombol Instal

d. Proses Pemasangan Aplikasi

Selanjutnya setelah menekan tombol install adalah memulai proses pemasangan aplikasi.

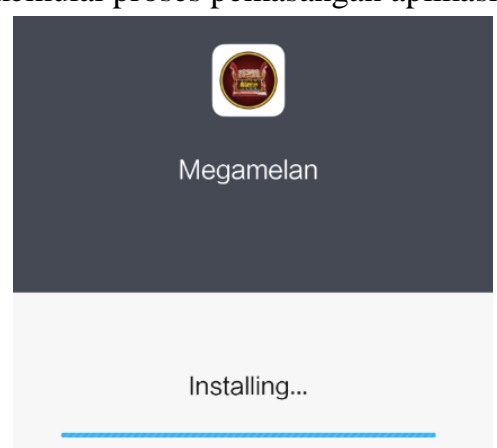

Gambar 28 Proses Pemasangan Aplikasi 
e. Aplikasi Telah Selesai Dipasang

Ketika proses pemasangan aplikasi sudah selesai maka akan muncul pemberitahuan bahwa aplikasi sudah selesai dipasang. Maka aplikasi sudah untuk digunakan.

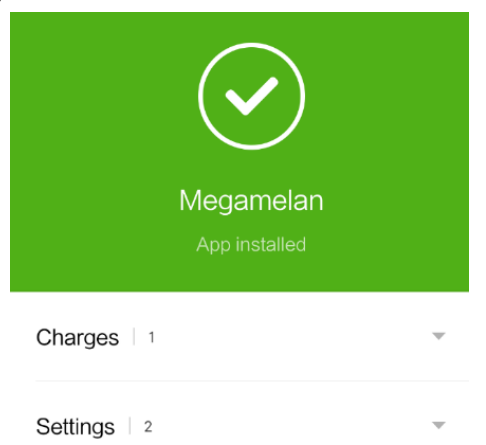

Gambar 29 Aplikasi Telah Selesai Dipasang

\subsection{Hasil Tahap Evaluasi}

Pengujian yang pertama yaitu pengujian white box. Pengujian white box dilakukan untuk mengetahui kebenaran dari proses pemanggilan source code aplikasi. Pengujian dilakukan oleh pengembang sendiri sesuai dengan angket yang sudah dirancang. Selanjutnya adalah pengujian black box. Pengujian black box dilakukan untuk mengetahui game yang dibuat sudah berjalan dengan baik dan benar dan dapat digunakan oleh orang lain. Pengujian dilakukan oleh lima mahasiswa yang menggunakan smartphone yang berbeda-beda untuk uji kebenaran proses dari game Musik Tradisional Bali Megamelan. Berdasarkan hasil pengujian pada kasus uji kebenaran proses, bahwa semua proses game pertama dijalankan sampai dengan selesai berfungsi dengan baik.

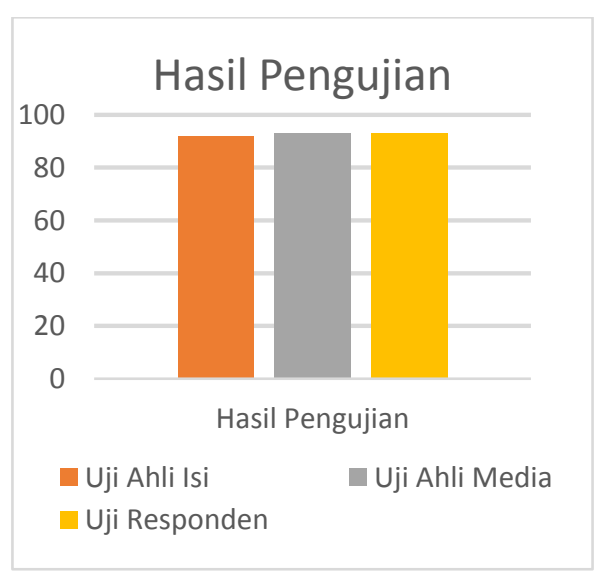

Gambar 30 Hasil Pengujian

Pengujian ahli isi dilakukan oleh satu orang, yaitu Bapak I Wayan Eka Putra Udyana, S.Sn. yang merupakan tamatan Institut Seni Indonesia Denpasar yang juga merupakan pelatih salah satu sanggar di desa Singapadu Tengah. Kriteria yang didapat dalam pengujian ahli isi adalah sangat sesuai dengan nilai 92\%. Salah satu aspek yang paling menonjol dalam aplikasi ini menurut ahli isi adalah cara memainkan instrumen gamelan sudah sama dengan cara memainkan gamelan aslinya. Hal tersebut merupakan salah satu tujuan dari aplikasi, yaitu membuat pemain dapat belajar cara memainkan gamelan dengan benar.

Pengujian ahli media dilakukan oleh dua dosen, yaitu Bapak I Gede Saindra Santyadiputra S.T., M..Cs. yang merupakan dosen di jurusan PTI UNDIKSHA dan Bapak I Made Ardwi Pradnyana, S.T.,M.T yang juga merupakan dosen di jurusan PTI UNDIKSHA. Dalam pengujian ahli media adapun masukan dari penguji, yaitu :

1. Ganti Button Return menjadi Continue

2. Buatkan bantuan pengguna aplikasi jangan hanya Learn to Play saja

3. Tambahkan Logo LCI, Undiksha, PTI pada menu About.

Masukan yang diberikan oleh penguji ahli media sudah diperbaiki dan dilakukan lagi pengujian siklus ke dua dan tidak terdapat lagi masukan dari penguji ahli media. Analisis untuk uji ahli media berada dalam kriteria sangat sesuai, dengan persentase 93\%. Dari hasil yang didapatkan dari pengujian dapat disimpulkan bahwa game Musik Tradisional Bali Megamelan sudah layak untuk melakukan uji lapangan.

Uji lapangan dilakukan oleh 20 orang untuk uji respon pengguna terhadap game Musik Tradisional Bali Megamelan. Analisis untuk uji respons pengguna media berada dalam kriteria sangat sesuai, dengan persentase $93 \%$. Berdasarkan hasil pengujian pada kasus uji respon pengguna hal paling menonjol yaitu, dengan adanya aplikasi ini saya lebih mudah untuk mengenal dan bermain Gamelan Gong Kebyar. Hal ini menunjukan bahwa tujuan dari game Megamelan sudah tercapai yaitu untuk mempermudah masyarakat khususnya kaum remaja untuk dapat memainkan dan dapat mengenal gamelan khususnya gamelan Gong Kebyar.

\section{KESIMPULAN}

Berdasarkan penelitian aplikasi “Aplikasi Game Musik Trandisional Bali Megamelan berbasis Multiplatform" yang telah dilakukan, maka diperoleh simpulan sebagai berikut. 
1. Aplikasi Game Musik Trandisional Bali Megamelan merupakan aplikasi yang buat untuk memperkenalkan kebudayaan bali dibidang seni gamelan khususnya gamelan Gong Kebyar.

2. Aplikasi Game Musik Trandisional Bali Megamelan dirancang dengan menggunakan model fungsional berupa UML (Unified Modeling Languange) yaitu use case diagram dan activity diagram yang dibuat dengan software Microsoft Visio yang terintegrasi dengan Microsoft Word sehingga lebih mudah untuk melakukan pembaharuan jika diperlukan.

3. Aplikasi Game Musik Trandisional Bali Megamelan telah berhasil diimplementasikan sesuai dengan perancangan yang telah dibuat sebelumnya. Aplikasi Game Musik Trandisional Bali Megamelan diimplementasikan menggunakan pemrograman $C \#$ dengan menggunakan game engine Unity 3D .

4. Fitur utama dari Aplikasi Game Musik Trandisional Bali Megamelan adalah play game yang terdapat 3 level yang terdiri dari level, easy (gamelan jegog), medium (gamelan calung) dan hard (gamelan penyacah). Setiap level dedapat lagu yang dapat dimainkan, total dari lagu yang bisa dimainkan adalah 10 lagu termasuk pada fitur learn to play.

5. Aplikasi Game Musik Trandisional Bali Megamelan dapat berjalan pada setiap jenis perangkat android dan iOS dengan sistem operasi Android yaitu Android 4.1 (Jelly bean) ke atas dan untuk iOS yaitu iOS 7 keatas. Secara umum untuk kesimpulan yang didapat setelah mengadakan pengujian respon yang dituangkan dalam bentuk angket respon.

6. Aplikasi Game Musik Trandisional Bali Megamelan dapat berjalan dengan baik pada setiap merk perangkat Android dan iOS yang diujikan dan semua kebutuhan fungsional dapat dijalankan. Secara umum untuk kesimpulan yang didapat setelah mengadakan pengujian respon yang dituangkan dalam bentuk angket respon, aplikasi ini mendapatkan respon sangat baik dilihat dari beberapa hasil pengujian angket yaitu : a) uji ahli isi dengan persentase $92 \%$, b) uji ahli media dengan persentase $93 \%$ dan c) uji respon dengan hasil persentase $93 \%$.

\section{DAFTAR PUSTAKA}

ANTARA, I. G. (2014). Game Jegog Berbasis Android. Retrieved Maret 14, 2017, from Karmapati: http://pti.undiksha.ac.id/karmapati/publikas i/

DAVID. (2014). Aplikasi Edukasi Music Traditional Arcade Berbasis Android. Retrieved Februari 21, 2017, from http://eprints.binus.ac.id/31395

DIAMIKA, I. W. (2015). Pengembanganaplikasi Instrumen Gamelan Semar Pegulingan Berbasis Android. Retrieved Februari 10, 2017, from http://pti.undiksha.ac.id/karmapati/publikas i/

GALANG, Y. B. (2014). Gamelan Gong Kebyar. Retrieved Maret 21, 2017, from Babad Bali: http://www.babadbali.com/seni/gamelan/ga -gam-gong-kebyar.htm

ISBAT, T. (2014). Pembuatan Musik Tradisional Modern Menggunakan Digital Audio Workstation.

MURUGANANTHAM. (2015). Developing of Econtent package by using ADDIE. International Journal of Applied Research.

PRIAWAN, M. Y. (2013). Teknologi, Smartphone, dan Android. Jurnal Ilmiah Teknologi Pendidikan.

RAI, I. W. (2002). Gong. Denpasar: Bali Mangsi.

SUHARTA, Y. (2011). Signifikansi Bahasa Inggris dalam Proses Belajar-Mengajar. Institut Seni Indonesia Denpasar.

WIBOWO, T. I. (2014). Pembuatan Musik Tradisional Modern Menggunakan Digital Audio Workstation. Retrieved Maret 18, 2017, from http:/repository.amikom.ac.id/files/Publikas i_10.11.4368.pdf

YUDHARTO, P. A. (2010). Perancangan Promosi Produk Edu-Game Melalui Event. Universitas Komputer Indonesia Bandung. Tugas Akhir Semester. 